\section{Pulmonary infiltration after exposure to home renovation dust: histopathology and microanalysis}

\author{
Kenneth Anderson, Charles P McSharry, \\ George P Morris, C H Stuart Cameron, \\ Douglas McLellan, David R H Vernon
}

\begin{abstract}
A subacute self-resolving illness associated with bilateral pulmonary infiltration developed in a patient following renovation in her home. This may have been related to exposure to silicaceous plaster dust which was found in an environmental sample as well as on microanalysis of a transbronchial lung biopsy specimen and bronchoalveolar lavage fluid.

(Thorax 1996;51:654-655)
\end{abstract}

Keywords: interstitial lung disease, building-related disease, silica.

A 29 year old woman was referred to the outpatient clinic because of a two month history of shortness of breath. She had no previous history of respiratory illness, the family history was unremarkable, and she was taking no regular medication. She worked as a secretary in a naturally ventilated office, smoked 15 cigarettes daily (10 pack years), and had no regular hobbies or pastimes involving organic dust or adhesives. She had travelled to various continents on holiday over the previous five years but could not recall any untoward illness or dust exposures elsewhere.

She and her fiancée had purchased a home which was about 100 years old. Immediately before the onset of her chest symptoms, panelling and plasterwork was removed in the bathroom of the house - a task which she completed over about 20 hours of active dusty work without respiratory protection. Immediately, and for several days after this work, small quantities of grey granular material were expectorated, and several night sweats occurred which settled despite continuing to sweep up the dust in the house. The onset of dyspnoea was more gradual

Serial lung volumes and transfer factor during the period of investigation and observation

\begin{tabular}{|c|c|c|c|c|c|}
\hline \multirow{2}{*}{$\begin{array}{l}\text { Lung function } \\
\text { parameters }\end{array}$} & \multicolumn{4}{|c|}{ Month } & \multirow{2}{*}{$\begin{array}{l}\text { Predicted } \\
\text { values }\end{array}$} \\
\hline & 0 & 2 & 5 & 12 & \\
\hline \multirow{2}{*}{$\begin{array}{l}\text { Forced expiratory volume in } \\
\text { one second } \\
\text { Vital capacity (l) } \\
\text { Total lung capacity (l) } \\
\text { Transfer factor (mmol CO/ } \\
\mathrm{kPa} / \mathrm{min} \text { ) }\end{array}$} & $\begin{array}{l}2 \cdot 49 \\
3 \cdot 44 \\
4 \cdot 1\end{array}$ & $\begin{array}{l}2 \cdot 85 \\
3 \cdot 5 \\
4 \cdot 39\end{array}$ & $\begin{array}{l}2 \cdot 76 \\
3 \cdot 71 \\
4.58\end{array}$ & $\begin{array}{l}2 \cdot 91 \\
3 \cdot 78 \\
4 \cdot 79\end{array}$ & $\begin{array}{l}(2 \cdot 45-4 \cdot 03) \\
(3 \cdot 06-4 \cdot 82) \\
(4 \cdot 19-6 \cdot 31)\end{array}$ \\
\hline & $5 \cdot 08$ & $6 \cdot 52$ & $5 \cdot 57$ & $7 \cdot 41$ & $(5 \cdot 4-8 \cdot 8)$ \\
\hline
\end{tabular}

and one month later she had to stop after climbing the stairs.

She looked well at rest and was apyrexial with no cyanosis, finger clubbing, or palpable lymphadenopathy. Cardiac examination was negative. There were no abnormal sounds on pulmonary auscultation. The abdomen, skin (a scar was present over the left deltoid in keeping with a previous BCG vaccination), joints, and nervous system were normal.

Bilateral, symmetrical haziness of variable density enclosing more discrete shadowing was present on the chest radiograph, mainly distributed in the middle thirds of each lung field and sparing the apices and costophrenic angles.

Serological testing was largely unhelpful: total immunoglobulins were normal (immunoglobulin $\mathrm{G} 12 \cdot 1 \mathrm{mg} / \mathrm{ml}$ ). No specific antibody was detected to $A$ fumigatus, $M$ faeni, pigeon antigen, or humidifier antigen. Antinuclear factor and rheumatoid factor were absent, and a respiratory infection screen was negative (including coccidioidomycosis and $\mathrm{Le}$ gionella $\mathrm{spp}$ ). The concentration of serum angiotensin converting enzyme was not increased. Total serum immunoglobulin $\mathrm{E}$ was not raised (32 IU $/ \mathrm{ml}$ ) and RAST to common inhalants was negative. A 1/10 dilution Mantoux skin test produced a $5 \mathrm{~mm}$ reaction. Peripheral blood differential count and immunophenotyping of lymphocyte subsets demonstrated normal cell numbers and proportions.

Pulmonary physiology detected a restrictive ventilatory defect with reduced transfer factor (table).

Analysis of bronchoalveolar lavage fluid by light microscopy and flow cytometry showed $22 \%$ lymphocytes (12\% CD 3, $7 \%$ CD 4 , and $5 \%$ CD8; $7 \%$ B cells and 3\% NK cells), 4\% neutrophils, $74 \%$ alveolar macrophages. There was no evidence of lymphocyte activation as assessed by expression of HLA-DR, CD71, CD25, and CD11b comparable with controls. Bacterial and fungal microscopy and culture (including mycobacterial species) of the lavage sample was negative.

Histological examination of lung tissue obtained by transbronchial lung biopsy (two months after the original exposure) showed widespread anthracotic pigment and birefringent particles, some within macrophages. Electron microscopic examination of the biopsy sample (figure) confirmed the presence of particulate material which, on microanalysis, was predominately silica with the addition of variable amounts of magnesium, aluminium, sulphur, calcium, and potassium. The particles measured from $0.4 \mu \mathrm{m}$ to over $9.0 \mu \mathrm{m}$ across their longest axis. They were mainly confined to the airspaces but were more frequently in adjacent macrophages while some were occasionally found embedded within collagen bundles. Similar particles were also identified in the bronchoalveolar lavage fluid.

Environmental samples of the bathroom dust were spread over formvar coated grids and examined by transmission and scanning electron microscopy. They varied in size and shape and measured from less than $0.25 \mu \mathrm{m}$ to over $4.0 \mu \mathrm{m}$ in diameter with larger aggregates of 


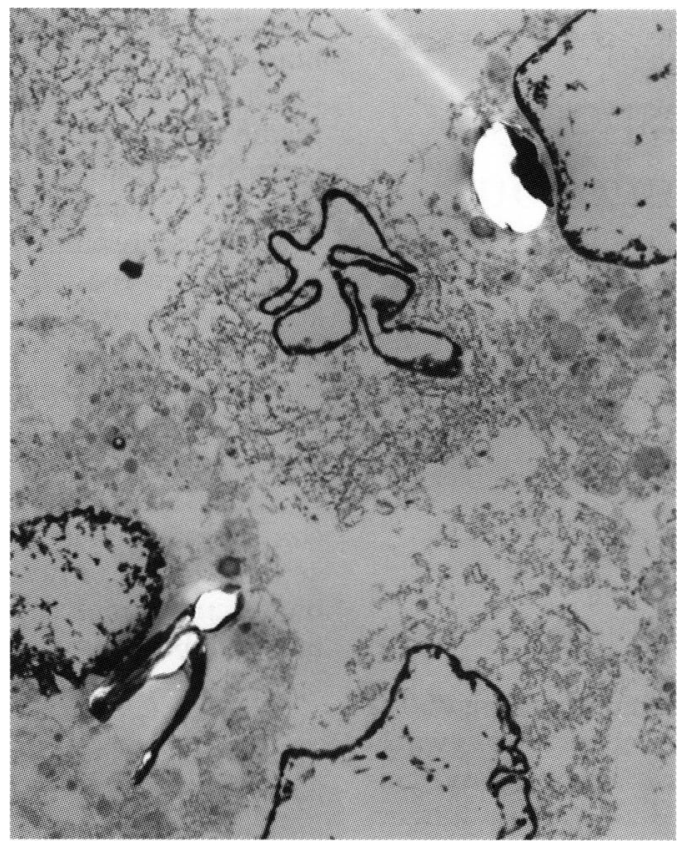

Electron micrograph ( $\times 8000$ magnification) of the transbronchial biopsy specimen showing particulate material within macrophages.

dust particles. Electron probe microanalysis showed a similar elemental distribution to that recorded in lung and lavage samples but with the occasional addition of a small peak in levels of iron.

In the following eight months there was a gradual recovery of her exercise reserve without specific treatment, the chest radiograph abnormalities resolved, and pulmonary function eventually recovered (table). She continued to live in the house but was never directly involved in the continuing renovation. Three years later she remains well and has no restriction to exercise.

\section{Discussion}

Pulmonary complications following exposure to silica dust have been extensively studied over many years and are usually associated with either acute illness ${ }^{1}$ or more chronic and insidious disease. ${ }^{2}$ Heppleston, however, described an animal experiment where the alveolar response to inhaled quartz was initially similar to alveolar proteinosis which was gradually cleared from rat lung without fibrosis. ${ }^{3}$ We have to speculate that the inhaled dose in our case was serendipitously lower than that which might cause acute silicosis, or that the constitution of the dust (similar to other more recent animal work) induced a less damaging reaction. ${ }^{4}$ Alternatively, the nature of the inhaled dust may have produced a different type of pulmonary response, predominantly in the interstitium, since our physiology studies suggested a more persistent reduction in gas transfer than overall loss of lung volume. Fortunately, the biopsy material - while too small in quantity to allow histological certainty - was sufficient in terms of ultrastructure. Open lung biopsy was not performed because the illness was subacute and, even from an early stage, seemed to be slowly resolving.

The dust in the room was mainly caused by the removal of the plasterwork which seemed to have had the various constituents of Portland cement - usually composed of calcinated silica clay with a small proportion of aluminate, sulphate, magnesium oxide, iron, and hexavalent chromium. ${ }^{5}$ Alveolar proteinosis has been reported in two subjects following occupational exposure to cement dust but there does not appear to be an equivalent of chronic silicosis in this industry where dust controls are rather less stringent than in others using silica ${ }^{67}$ This does not imply absence of an effect, particularly after acute exposure, since both our patient and the case reported by Rosen and colleagues ${ }^{6}$ had a component of fever following inhalation. The fate of calcium silicate after inhalation is not known - pulmonary clearance may be rapid $^{8}$ although fibrogenesis has been demonstrated by experimental work in animals when the cement dust contained a low concentration of quartz. ${ }^{9}$

We cannot be certain that the pulmonary response was entirely related to the silicon and the other elements detected, however similar ultrastructural appearances have been reported by others following exposure to silica. ${ }^{10}$ There may have been other materials in the dust which we did not identify that were partially or wholly responsible for the pulmonary infiltrate and which were gradually cleared so that her symptoms, radiology, and pulmonary function improved. Nevertheless, after a discrete exposure to silicaceous dust, a subacute selflimiting disease developed in unexpected circumstances which we do not believe has been reported previously.

1 Beuchner HA, Ansari A. Acute silico-proteinosis. Chest 1969;55:274-84.

2 Ziskind M, Jones RN, Weill H. Silicosis. Am Rev Respir Dis 1976;113:643-65.

3 Heppleston AG. Atypical reaction to inhaled silica. Nature 1967;213:199.

4 Schapira RM, Ghio AJ, Effros RM, Morrisey J, Almagaro UA, Dawson CA, et al. Hydroxyl radical production and lung injury in the rat following silica or titanium dioxide instillation in vivo. Am $\mathcal{F}$ Respir Cell Mol Biol 1995;12: $220-6$.

5 Lea FM. The chemistry of cement and concrete. 3rd ed. New York: Chemical Publishing Co Inc, 1970:1-19, 158-65.

6 Rosen SH, Castleman B, Liebow AA. Pulmonary alveolar proteinosis. N Engl f Med 1958;258:1123-42.

7 McCunney RJ, Godefroi R. Pulmonary alveolar proteinosis and cement dust: a case report. F Occup Med 1989;31: 233-7.

8 Holt PF. Silicates other than asbestos: mineral silicates and cement. In: Inhaled dust and disease. Chichester: John Wiley and Sons, 1987:197-208.

9 Einbrodt HJ, Hentschel D. Animal experiments with dusts from working places of a cement works. Int Arch Gewerbepath Gewerbehyg 1966;22:354-66.

10 Roggli VL, Brody AR. Imaging techniques for application to lung toxicology. In: Gardner DE, Crapo JD, Massaro EJ eds. Toxicology of the lung. New York:Raven Press, 1988: $117-45$. 